\title{
A Cross-National Study on Healthcare Safety Climate and Staff Attitudes to Disclosing Adverse Events between China and Japan
}

\author{
Xiuzhu Gu and Kenji Itoh \\ Dept. of IE and Management, Tokyo Institute of Technology \\ 2-12-1 Oh-okayama Meguro-ku, Tokyo 152-8552, Japan \\ \{xiuzhu.g.aa,itoh.k.aa\}@m.titech.ac.jp
}

\begin{abstract}
The present paper reports comparative results of safety climate in healthcare and staff attitudes to error reporting and interaction with patients between China and Japan. Using two language versions of questionnaire, we collected response data from hospital staff in China (in 2008) and Japan (in 2006). Significant differences were observed in most dimensions of safety climate between these two countries, though not in the same direction in terms of positive or negative nature. In contrast, there was a uniform national difference in staff attitudes to error reporting. Chinese doctors and nurses being significantly less willing than their Japanese colleagues to engage in any action or interaction with patients after an adverse event, regardless of the severity of the event. Finally, we discuss possible sources of these differences in safety climate and staff attitudes between the two countries, and some implications for improving healthcare safety climate.
\end{abstract}

Keywords: Healthcare safety climate; incident reporting; adverse event; crossnational survey.

\section{Introduction}

As in western countries and Japan, there has been a rapid increase of concerns with patient safety in China. Safety culture has been widely recognized as being of major importance to patient safety [1], and therefore a number of studies have been carried, aiming at developing safety culture tools or instruments and applying questionnaire surveys to measuring and diagnosing a specific healthcare organization as well as at the nation level in these countries - e.g., in the USA [2] and Europe [3]. In recent years, safety culture has also drawn great attention in China. A sign of the increasing awareness of the importance of safety culture is that the Chinese government has established strategic goals for improving patient safety in 2008, including a nonpunitive management style to encourage voluntary incident reporting in healthcare organizations as one of ten major goals [4]. While in recent years, a small number of studies have appeared of safety culture in domains outside healthcare in China- e.g. [5] [6], a few other studies have also been made in healthcare - perhaps inspired by the strategic goals laid down by the Chinese government as mentioned [7] [8].

The original version of this chapter was revised: The copyright line was incorrect. This has been corrected. The Erratum to this chapter is available at DOI: 10.1007/978-3-642-11750-3_10

P. Palanque, J. Vanderdonckt, and M. Winckler (Eds.): HESSD 2009, LNCS 5962, pp. 44-53, 2010.

(C) Springer-Verlag Berlin Heidelberg 2010 
But no comprehensive, systematic survey has been carried out yet in the healthcare sector. For instance, among the few Chinese studies relevant to this field, a safety culture assessment was recently published reporting on nurse responses to a small questionnaire having 19 items [8].

Given the background mentioned above, it is an urgent goal to uncover safety culture in Chinese healthcare. In particular, to highlight its important characteristics, cross-national studies may be required, comparing with other country samples using the same questionnaire. Motivated by these requirements, we conducted a safety culture survey in China, collecting data by applying a Chinese translation of a questionnaire which was used for a Japanese survey [9]. Comparative analyses were performed using the two country samples, aiming at identifying the impacts of different healthcare systems and safety regulations as well as national culture on safety culture or climate. The terms "safety culture" and "safety climate" suggest somewhat different approaches to studying and modeling the shared understanding that members of an organization or group may have: "culture" is usually meant to refer to the long-term and relatively unchanging and mostly tacit values, norms and assumptions of a group, whereas "climate" is usually meant to refer to the more context-based and more changeable ones [10] [11]. Hereafter we use the term, safety climate with its emphasis on the local, changeable nature and explicit attitudes and perceptions.

In the present paper, we report results of cross-national analysis between China and Japan in healthcare safety climate and staff attitudes to error reporting and interactions with the patient after an adverse event. We discuss possible reasons or factors contributing to variations of the safety climate between these two countries. Based on the discussions, we also explore some implications for safer healthcare systems in the near future.

\section{Questionnaire}

The questionnaire used in this study was a Chinese translation of one used in a Japanese survey [12]. The Chinese version of questionnaire was thoroughly checked from professional points of view by several doctors and nurses working in the hospital from which data were collected as well as consistency of the two language versions. The questionnaire comprised four sections, among which this paper focused on the first two sections, as well as a demographic section.

The first section was comprised of 57 question items to elicit respondents' perceptions of their job, hospital management, and factors that might impact on safety performance. Respondents were asked to rate their agreement or disagreement with each statement on a five-point Likert type scale, ranging from 'strongly disagree' to 'strongly agree'. This section was originally adapted from the instrument used for "Operating Team Resource Management Survey" developed by Robert Helmreich and his research group [13].

In the second section, respondents were asked about their behavior and actions in terms of reporting own errors and interaction with patients that have been victims of such errors. Respondents' reactions were elicited as responses to three fictitious incident cases (vignettes) having different outcome severity: Cases A (near-miss), B 
(mild outcome) and $\mathrm{C}$ (severe outcome). The respondents were asked to read each case and subsequently rate the likelihood of engaging in various actions described in the questionnaire. The likelihood rating was also made on a five point Likert-type scale ranging from 'definitely no' to 'definitely yes'. The incident cases and questions were reproduced from those of the Danish Patient Safety Questionnaire [14].

The Chinese survey was carried out between October and December 2008, collecting data from doctors, nurses, pharmacists and other professionals working in a university hospital - having approximately 850 beds, 650 doctors and 700 nurses working - located in Shanghai, China. Responses and response rates of each professional group are shown in Table 1, which also includes the response information of the Japanese survey [9] which was used for cross-national analysis in this study.

Table 1. Number of responses used for cross-national analysis

\begin{tabular}{lcccc}
\hline \multirow{2}{*}{$\begin{array}{l}\text { Professional } \\
\text { groups }\end{array}$} & $\begin{array}{c}\text { Number of } \\
\text { responses }\end{array}$ & Response rate & $\begin{array}{c}\text { Number of } \\
\text { responses }\end{array}$ & Response rate \\
\hline Doctor & 388 & $78 \%$ & 1,005 & $51 \%$ \\
Nurse & 611 & $87 \%$ & 17,858 & $88 \%$ \\
Pharmacist & 37 & $74 \%$ & 542 & $48 \%$ \\
Others/NA & 20 & $40 \%$ & 2,261 & - \\
\hline Total & 1,056 & $81 \%$ & 21,666 & $84 \%$ \\
\hline
\end{tabular}

\section{Results of Cross-National Analysis}

\subsection{Healthcare Safety Climate}

As a framework for cross-national analysis of safety climate, we employed a twelve dimensional model [9], which was derived by applying the principal component analysis to the Japanese sample of the 2006 survey. Table 2 describes the meaning of each safety climate dimension, and Cronbach's $\alpha$ is also shown when applying the model to the Chinese sample. As can be seen in this table, Cronbach's $\alpha$ was very low for some dimensions. Therefore, we compared the two countries' safety climate in terms of dimensions having higher than 0.4 of Cronbach's $\alpha$. The threshold of 0.4 is unusually low, and the standard threshold of $\alpha$ for accepting a construct or factor is 0.7 [15]. However, it may be argued that satisfactory levels of alpha depend on test use and interpretation. Even relatively low levels of criterion reliability do not seriously attenuate validity coefficients [16]. A lower threshold may be applied, especially with factors that comprise a small number of items [17]. Still, we do not propose to apply a lower than usual threshold for identifying the reliability of a construct. For the rest of dimensions, we made item-based comparisons between the Chinese and the Japanese sample for a few typical or representative items to a specific safety climate dimension, e.g., "human error is inevitable" and "errors are a sign of incompetence" for the dimension on recognition of human error. 
Table 2. Dimensions of safety climate for comparisons between China and Japan [9]

\begin{tabular}{|c|c|}
\hline $\begin{array}{l}\text { Safety Climate dimensions } \\
\text { (Cronbach's } \alpha)\end{array}$ & Description \\
\hline $\begin{array}{ll}\text { I. } & \text { Recognition of } \\
\text { communication } \\
(\alpha=0.700)\end{array}$ & $\begin{array}{l}\text { Acknowledgement of importance of communication } \\
\text { and coordination during performing a job within an } \\
\text { organization or among team members }\end{array}$ \\
\hline $\begin{array}{l}\text { II. Morale and motivation } \\
(\alpha=0.699)\end{array}$ & $\begin{array}{l}\text { Employees' morale and motivation for work and } \\
\text { organization }\end{array}$ \\
\hline $\begin{array}{ll}\text { III. } & \text { Power distance } \\
(\alpha=0.675)\end{array}$ & $\begin{array}{l}\text { Psychological distance between leaders or superiors } \\
\text { and subordinate members. In a large power distance } \\
\text { organization there may be bureaucratic, authoritative } \\
\text { atmosphere, limited open communication between } \\
\text { leaders and their subordinates within a workplace } \\
\text { and lack of communication between departments }\end{array}$ \\
\hline $\begin{array}{l}\text { IV. Recognition of stress effects } \\
\text { on own performance. } \\
(\alpha=0.327)\end{array}$ & $\begin{array}{l}\text { Realistic understanding and recognition about } \\
\text { effects of stress, fatigue and other psychological } \\
\text { factors on their own work performance. }\end{array}$ \\
\hline $\begin{array}{ll}\text { V. } & \text { Trust in management } \\
(\alpha=0.288)\end{array}$ & $\begin{array}{l}\text { Staff trust in hospital management systems, senior } \\
\text { managers, and leaders/superiors in their department } \\
\text { or organization }\end{array}$ \\
\hline $\begin{array}{ll}\text { VI. Safety awareness } \\
(\alpha=0.389)\end{array}$ & $\begin{array}{l}\text { Staff members' awareness of safety for their jobs } \\
\text { and patient safety issues. High awareness members } \\
\text { are likely to take risk avoidance behavior/attitudes } \\
\text { during task performance }\end{array}$ \\
\hline $\begin{array}{l}\text { VII. Awareness of own } \\
\text { competence } \\
(\alpha=0.630)\end{array}$ & $\begin{array}{l}\text { Staff members' awareness of their own competence } \\
\text { and skills. High awareness members believe staff } \\
\text { competence and skills are the most important factors } \\
\text { for working in a hospital }\end{array}$ \\
\hline $\begin{array}{l}\text { VIII. Collectivism- individualism } \\
(\alpha=0.282)\end{array}$ & $\begin{array}{l}\text { Proportion of staff members taking team-oriented or } \\
\text { collectivistic behavior in an organization }\end{array}$ \\
\hline $\begin{array}{ll}\text { IX. } & \text { Cooperativeness } \\
(\alpha=0.055)\end{array}$ & $\begin{array}{l}\text { Proportion of staff members taking cooperative } \\
\text { attitudes and behaviors within an organization }\end{array}$ \\
\hline $\begin{array}{ll}\text { Recognition of stress } \\
\text { management for team } \\
\text { members }(\alpha=0.534)\end{array}$ & $\begin{array}{l}\text { Realistic acknowledgement or awareness about } \\
\text { other team members' stress and fatigue levels while } \\
\text { they are working by team }\end{array}$ \\
\hline $\begin{array}{ll}\text { XI. } & \text { Seniority dependency } \\
& (\alpha=0.435)\end{array}$ & $\begin{array}{l}\text { Tend to depend on seniors or seniority system for } \\
\text { work management in an organization. }\end{array}$ \\
\hline $\begin{array}{l}\text { XII. Recognition of human error } \\
(\alpha=0.050)\end{array}$ & $\begin{array}{l}\text { Realistic acknowledgement of human errors within a } \\
\text { department/organization }\end{array}$ \\
\hline
\end{tabular}

According to this procedure of the cross-national comparisons, Table 3 shows percentage agreements and disagreements of both doctor and nurse groups in China and Japan for each of the selected dimensions. The percentage [dis]agreement is referred to as a proportion of a specific respondent group, e.g., Chinese doctors and Japanese nurses, that strongly or slightly [dis]agreed with the items comprised in a given dimension. This index is computed as follows: before the mean score calculation, figures of responses were reversed for an item which has a negative meaning to a dimension label, i.e., response rank " 1 " was changed to " 5 ", and vice versa. A possible range of the mean score (i.e., 1.0-5.0) was divided into five ranks, 
the top two ranks, 3.41-5.00, are allocated to an 'agreement' class, and the last two, 1.00-2.60, to a 'disagreement'. Table 3 also includes significance levels computed by the Mann-Whitney test between Chinese and Japanese staff for each dimension of safety climate.

As can be seen from Table 3, there were significant differences between Chinese and Japanese doctors for all dimensions of safety climate except for morale and motivation. For some dimensions, the safety climate elicited from Chinese doctors was more negative than those of Japanese: Chinese doctors' recognition of communication and stress management was weaker than that of the Japanese; and the power distance was much larger in the Chinese hospital. In contrast, Chinese doctors were more aware of their own skills and competence, and their dependency on senior staff and a seniority system was significantly weaker than Japanese.

As results of item-based comparisons of staff responses, significant differences were observed for most of statements, i.e., 49 out of 57 items for doctors and 51 items for nurses, between the two countries. Regarding error-related issues, Chinese doctors showed themselves less realistic recognition of human errors than Japanese. A greater number of doctors agreed with the statement "errors are a sign of incompetence" in China than Japan $(p<0.001$, agreement rate of Chinese and Japanese were $23 \%$ and $7 \%$, respectively), and disagreed with the item "human error is inevitable" ( $p<0.001$; disagreement: $51 \%$ and $10 \%$ - almost all Japanese doctors accepted this statement).

Table 3. Safety climate comparisons between Chinese and Japanese healthcare staff

\begin{tabular}{|c|c|c|c|c|c|c|}
\hline \multirow{2}{*}{ Safety climate dimensions } & \multicolumn{2}{|c|}{ China } & \multicolumn{2}{|c|}{ Japan } & \multicolumn{2}{|c|}{ p (Mann-Whitney) } \\
\hline & Dr. & Ns. & Dr. & Ns. & Dr. & Ns. \\
\hline $\begin{array}{ll}\text { I. } & \begin{array}{l}\text { Recognition of } \\
\text { communication }\end{array} \\
\end{array}$ & $\begin{array}{r}73 \% \\
4 \%\end{array}$ & $\begin{array}{r}76 \% \\
2 \%\end{array}$ & $\begin{array}{r}95 \% \\
0 \%\end{array}$ & $\begin{array}{r}95 \% \\
0 \%\end{array}$ & 0.000 & 0.000 \\
\hline Morale \& motivation & $\begin{array}{r}60 \% \\
8 \%\end{array}$ & $\begin{array}{r}65 \% \\
7 \%\end{array}$ & $\begin{array}{r}65 \% \\
9 \%\end{array}$ & $\begin{array}{l}47 \% \\
19 \%\end{array}$ & 0.192 & 0.001 \\
\hline III. Power distance & $\begin{array}{l}17 \% \\
39 \%\end{array}$ & $\begin{array}{l}19 \% \\
41 \%\end{array}$ & $\begin{array}{r}1 \% \\
84 \%\end{array}$ & $\begin{array}{r}1 \% \\
82 \%\end{array}$ & 0.000 & 0.000 \\
\hline $\begin{array}{l}\text { VII. Awareness of own } \\
\text { competence }\end{array}$ & $\begin{array}{r}73 \% \\
2 \% \\
\end{array}$ & $\begin{array}{r}75 \% \\
2 \% \\
\end{array}$ & $\begin{array}{r}50 \% \\
6 \% \\
\end{array}$ & $\begin{array}{l}32 \% \\
12 \% \\
\end{array}$ & 0.000 & 0.000 \\
\hline $\begin{array}{ll}\text { X. Recognition of stress } \\
\text { mgt. for members }\end{array}$ & $\begin{array}{r}72 \% \\
3 \%\end{array}$ & $\begin{array}{r}70 \% \\
4 \%\end{array}$ & $\begin{array}{r}84 \% \\
1 \%\end{array}$ & $\begin{array}{r}81 \% \\
1 \%\end{array}$ & 0.005 & 0.000 \\
\hline Seniority dependency & $\begin{array}{r}67 \% \\
6 \%\end{array}$ & $\begin{array}{r}57 \% \\
6 \%\end{array}$ & $\begin{array}{r}85 \% \\
1 \%\end{array}$ & $\begin{array}{r}55 \% \\
7 \%\end{array}$ & 0.000 & 0.051 \\
\hline
\end{tabular}

Upper row: \% agreement, Low row: \% disagreement.

Similar to doctors' responses - but with a slightly different trend - Chinese nurses exhibited significantly negative views of or attitudes to some dimensions of safety climate compared to their Japanese colleagues, i.e., weaker recognition of communication, larger power distance, and weaker recognition of stress management for team members. As can be seen from Table 3, however, Chinese nurses revealed more positive reactions to two dimensions than Japanese: higher morale and motivation, and much stronger awareness of their own competence - the difference for the latter dimension was identical to that of the doctor group. Similar differences 
to those between Japanese and Chinese doctors were also found in the nurse samples. But because of the low reliability of the constructs (low alpha) the comparisons were made on an item comparison basis. Again, we found a much less realistic recognition of errors by Chinese nurses compared to their Japanese colleagues.

\subsection{Staff Attitudes to Error Reporting}

Using responses to the second section of the questionnaire, we analyzed crossnational differences between China and Japan in healthcare staff attitudes to error reporting (for Cases A to $\mathrm{C}$ ) and interactions with patients (for Cases B and C) based on professional groups. Large differences were observed between the two countries for both doctor and nurse attitudes, and characteristics of cross-national differences were shared between the doctor and the nurse group. The comparative results of the two country samples are shown for the doctor and nurse group respectively in Table 4 and 5, based on three cases of outcome severity in terms of percentage agreement and disagreement (strongly or slightly) with each action.

Table 4. Attitudes to error reporting comparisons between Chinese and Japanese doctors

\begin{tabular}{lc|rrrr|l}
\hline \multirow{2}{*}{ Actions } & \multirow{2}{*}{ Case } & \multicolumn{2}{|c}{ China } & \multicolumn{2}{c|}{ Japan } & \multirow{2}{*}{} \\
& & \% agr. & $\%$ disag. & $\%$ agr. & $\%$ disag. & \\
\hline \multirow{2}{*}{ Keep the event secret } & A & $30 \%$ & $43 \%$ & $7 \%$ & $83 \%$ & 0.000 \\
& B & $29 \%$ & $40 \%$ & $3 \%$ & $87 \%$ & 0.000 \\
& $\mathrm{C}$ & $24 \%$ & $42 \%$ & $2 \%$ & $94 \%$ & 0.000 \\
\hline \multirow{2}{*}{ Report to leader or } & $\mathrm{A}$ & $48 \%$ & $22 \%$ & $78 \%$ & $9 \%$ & 0.000 \\
doctor in charge & $\mathrm{B}$ & $61 \%$ & $13 \%$ & $91 \%$ & $3 \%$ & 0.000 \\
& $\mathrm{C}$ & $61 \%$ & $12 \%$ & $96 \%$ & $1 \%$ & 0.000 \\
\hline Write in patient's case & $\mathrm{B}$ & $28 \%$ & $37 \%$ & $76 \%$ & $9 \%$ & 0.000 \\
record & $\mathrm{C}$ & $30 \%$ & $29 \%$ & $87 \%$ & $4 \%$ & 0.000 \\
\hline \multirow{2}{*}{ Report to the local } & $\mathrm{A}$ & $30 \%$ & $29 \%$ & $66 \%$ & $16 \%$ & 0.000 \\
system & $\mathrm{B}$ & $38 \%$ & $23 \%$ & $73 \%$ & $7 \%$ & 0.000 \\
& $\mathrm{C}$ & $42 \%$ & $20 \%$ & $93 \%$ & $2 \%$ & 0.000 \\
\hline Inform patient of the & $\mathrm{B}$ & $25 \%$ & $39 \%$ & $52 \%$ & $17 \%$ & 0.000 \\
error and risk & $\mathrm{C}$ & $36 \%$ & $32 \%$ & $92 \%$ & $2 \%$ & 0.000 \\
\hline \multirow{2}{*}{ Admit own error } & $\mathrm{B}$ & $27 \%$ & $38 \%$ & $52 \%$ & $17 \%$ & 0.000 \\
& $\mathrm{C}$ & $36 \%$ & $31 \%$ & $86 \%$ & $4 \%$ & 0.000 \\
\hline \multirow{2}{*}{ Apologize to patient } & $\mathrm{B}$ & $40 \%$ & $31 \%$ & $62 \%$ & $14 \%$ & 0.000 \\
& $\mathrm{C}$ & $43 \%$ & $24 \%$ & $89 \%$ & $3 \%$ & 0.000 \\
\hline
\end{tabular}

$\%$ agr. : \% agreement (\% of respondents definitely or slightly agree with the statement).

$\%$ disag. : $\%$ disagreement ( $\%$ of respondents definitely or slightly disagree with the statement).

Table 4 showed that the attitudes of Chinese and Japanese doctors are, in all the three cases, highly significantly different. Chinese doctors had weaker willingness to report the error, and they also showed themselves less likely to inform about the error or apologize to the patient than Japanese doctors. With the case's severity increased, Japanese doctors showed higher willingness to report the error and do interaction with the patient, for example, inform patient of the error and risk; while Chinese doctors' 
Table 5. Attitudes to error reporting comparisons between Chinese and Japanese nurses

\begin{tabular}{lc|rrrr|l}
\hline \multirow{2}{*}{ Actions } & \multirow{2}{*}{ Case } & \multicolumn{2}{|c|}{ China } & \multicolumn{2}{c|}{ Japan } & \multirow{2}{*}{} \\
& & \% agr. & $\%$ disag. & $\%$ agr. & $\%$ disag. & $p$ \\
\hline \multirow{2}{*}{ Keep the event secret } & A & $23 \%$ & $47 \%$ & $8 \%$ & $79 \%$ & 0.000 \\
& B & $28 \%$ & $43 \%$ & $1 \%$ & $94 \%$ & 0.000 \\
& $\mathrm{C}$ & $26 \%$ & $41 \%$ & $1 \%$ & $92 \%$ & 0.000 \\
\hline \multirow{2}{*}{ Report to leader or } & $\mathrm{A}$ & $54 \%$ & $18 \%$ & $80 \%$ & $9 \%$ & 0.000 \\
doctor in charge & $\mathrm{B}$ & $65 \%$ & $9 \%$ & $93 \%$ & $3 \%$ & 0.000 \\
& $\mathrm{C}$ & $63 \%$ & $9 \%$ & $92 \%$ & $4 \%$ & 0.000 \\
\hline Write in patient's case & $\mathrm{B}$ & $28 \%$ & $32 \%$ & $73 \%$ & $7 \%$ & 0.000 \\
record & $\mathrm{C}$ & $29 \%$ & $28 \%$ & $71 \%$ & $6 \%$ & 0.000 \\
\hline \multirow{2}{*}{ Report to the local } & $\mathrm{A}$ & $36 \%$ & $21 \%$ & $71 \%$ & $13 \%$ & 0.000 \\
system & $\mathrm{B}$ & $38 \%$ & $18 \%$ & $91 \%$ & $3 \%$ & 0.000 \\
& $\mathrm{C}$ & $42 \%$ & $15 \%$ & $90 \%$ & $3 \%$ & 0.000 \\
\hline Inform patient of the & $\mathrm{B}$ & $27 \%$ & $32 \%$ & $43 \%$ & $14 \%$ & 0.000 \\
error and risk & $\mathrm{C}$ & $35 \%$ & $31 \%$ & $71 \%$ & $5 \%$ & 0.000 \\
\hline \multirow{2}{*}{ Admit own error } & $\mathrm{B}$ & $33 \%$ & $30 \%$ & $44 \%$ & $14 \%$ & 0.000 \\
& $\mathrm{C}$ & $37 \%$ & $30 \%$ & $57 \%$ & $9 \%$ & 0.000 \\
\hline \multirow{2}{*}{ Apologize to patient } & $\mathrm{B}$ & $44 \%$ & $26 \%$ & $66 \%$ & $6 \%$ & 0.000 \\
\hline
\end{tabular}

$\%$ agr. : \% agreement (\% of respondents definitely or slightly agree with the statement).

$\%$ disag. : $\%$ disagreement ( $\%$ of respondents definitely or slightly disagree with the statement).

willingness doesn't increase so much. About error reporting, both Chinese and Japanese doctors prefer reporting to leader or doctor in charge than other ways.

Similar to doctors, there were also highly significant differences between Chinese and Japanese nurses in their attitudes for all error reporting actions and reactions with the patient regardless of the levels of outcome severity. As shown in Table 5, Chinese nurses exhibited more negative attitudes to following a policy of openness than their Japanese colleagues for every action offered in the questionnaire, e.g., they were more likely to keep the event to themselves; less willing to report the error to their leader or doctor in charge; less willing to submit an incident report to the local system; less likely to inform the patient about the event and future health risk; more reluctant to admit their own errors; and more reluctant to apologize to the patient.

Conversely, almost all Japanese nurses indicated that they would report the event to their leader or a doctor in charge, and submit it to their local system for the two cases involving injury, i.e., Cases B and C, and they were significantly more likely to do so than for the non-injured near-miss case A, while there were no large differences in their willingness to take these reporting actions between the mild and the severe outcome case. However, their interactions with the patient, e.g., apology to the patient, informing the patient about the event and the future risk, and admittance of their own errors, were more positively affirmed in the severe than in the mild outcome case. In contrast, among the Chinese nurses no large differences were observed between the cases involving injury, i.e., $\mathrm{B}$ and $\mathrm{C}$, in their willingness to do error reporting or to interact with the patient. 


\section{Discussion: Sources of Cross-National Differences}

In the present paper, we applied the safety climate construct derived in a previous study [9] to a Chinese sample as an analysis framework for making cross-national comparisons. This application of the Japanese model seems to be a major reason why Cronbach's $\alpha$ calculated were very low for some dimensions, in particular, for recognition of human error, cooperativeness and recognition of stress effects on one's own performance. All of these dimensions are closely connected to issues concerning human factors at work and their effects on work performance. Here we refer to 'human factors' as the collection of knowledge about how humans perform, cognitively, socially and physiologically, in work contexts and especially contexts involving technological systems and safety critical operations. The low internal reliability of these dimensions may indicate that Chinese respondents understand the meaning of the component items in a slightly different way than intended and different from the way in which the Japanese respondents understand them. This difference in understanding the items may have to with the lack of familiarity that the Chinese respondents have with notions about performance shaping factors such as the effects of fatigue or poor communication on performance. This speculation is supported by the fact that the Chinese healthcare staff is unfamiliar with safety training in the style of CRM (crew resource management) [13], and are thus not familiar with human factors as described above and especially with human cognitive limitations in work performance.

Based on the cross-national analyses with the Japanese data, it appears as important characteristics of safety climate in Chinese healthcare that doctors' recognition of communication for safety as well as the role of stress management for team members is very weak. It may be the reason why improving the effective communication among healthcare staff was required to include as one of important patient safety goals established by the government in 2008 [4]. At the same time, power distance was larger and the doctors' recognition of human error issues was not enough realistic. For instance, a number of Chinese doctors disagreed strongly with the statement, "human error is inevitable". This point of view is presumably based on their concepts of human error mechanism and possibly derived by an idea of the "true professional" as being infallible; and again, this is presumably linked to the fact that they have never received any training in human performance for safety critical tasks.

A larger power distance may be conjectured to be a major source of the greater reluctance of Chinese staff to reporting errors and adverse events. According to interviews with risk managers in the hospital surveyed, healthcare staff would receive punishment when they were found to make an error. This finding may be supported by the result identified by Liu et al. [8], that there was a punitive safety culture in hospitals in China. In addition, patients in China have a possibility to initiate complaint procedures and apply for compensation - a course of action which is not open to Japanese patients in the same way. Again, the threat of punishment and complaints would naturally lead Chinese doctors and nurses to be very reluctant to report their own errors or be in any way open about them.

When confronted with a case involving an error leading to a serious outcome, Chinese staff became slightly more willing to report the error and to interact with the patient. In contrast, Japanese nurses expressed a higher willingness to report the case 
if it involved a milder outcome rather than a severe one; they also showed themselves more reluctant to interact with patient - offer an apology to the patient or admit their own error - than to report the event to their leader or to the local system. However, it may well be the case that the chief reason why the Chinese respondents express a greater willingness to report the severe incident than the minor one is because the error is obvious and impossible to hide. A major reason for consistent levels of error reporting attitudes expressed by Japanese nurses between the two cases involved injury seems to be based on a widespread safety practice or custom within the nursing department: nurses are always pushed by their leaders and senior staff to report their errors, and in fact are strongly encouraged to do so ('must' do so in many hospitals) when they involve in an injured event - even very minor one - although incident reporting is formally operated voluntarily in most Japanese hospitals.

\section{Conclusion}

This study identified some important characteristics of healthcare safety climate in China by comparing with the Japanese sample: Chinese staff put much less weight on the importance of communication among staff members than Japanese, and they showed less realistic recognition of human performance and human error issues. Also, larger power distance was identified in the Chinese healthcare settings. In contrast, Chinese nurses' morale and motivation as well as their awareness of own competencies were significantly higher than those of Japanese nurses. Chinese staff was more likely to have negative attitudes to error reporting and to interaction with patients who suffered an adverse event than Japanese staff.

From the results and discussions obtained in this paper, we would suggest that safety training particularly involving human factors aspects should be required to foster a positive safety climate in China. Negative staff attitudes to adverse event reporting may be primarily created by fear of sanctions and disrepute. Behind the reluctance to report errors - and thus be able to learn from these - there is, we suggest a blame culture affecting Chinese healthcare, as indeed also suggested by the hospital risk managers through our interviews. A large power distance observed in the Chinese sample might also play a role in discouraging openness and adverse event reporting. Therefore, we would suggest, as one of the urgent hospital-wide initiatives in China, to steer risk management in the direction of a non-punitive style, and to adopt safety training, particularly including learning from errors and accidents. We believe this in turn would contribute to establishing an effective learning culture in healthcare and thus to greater patient safety.

\section{Acknowledgments}

This work was in part supported by Grant-in-Aid for Scientific Research A (2) (No. 18201029), Japan Society for the Promotion of Science. We would like to acknowledge Henning Boje Andersen, Senior Scientist in Technical University of Denmark for his insightful discussions and comments. We are also grateful to the risk manager and risk management personnel in the hospital surveyed for supporting data collection and valuable information about their risk management procedures and systems. 


\section{References}

1. Itoh, K., Andersen, H.B., Madsen, M.D.: Safety Culture in Healthcare. In: Carayon, P. (ed.) Handbook of Human Factors and Ergonomics in Healthcare and Patient Safety, pp. 199-216. Lawrence Erlbaum Associates, Mahwah (2006)

2. Kohn, L.T., Corrigan, J.M., Donaldson, M.S. (eds.): To Err Is Human: Building a Safer Health System. National Academy Press, Washington (1999)

3. Department of Health: An Organisation with a Memory: Report of an Expert Group on Learning from Adverse Events in the National Health Service Chaired by the Chief Medical Officer, Stationery Office, London (2000)

4. Chinese Hospital Association, China (2009), http://www.cha.org.cn/GD/ GeneralDocument/GDContent. aspx?Content Id=608\&ClassId= $167 \&$ Channel Id=38 (accessed 14 September)

5. Lin, S., Tang, W., Miao, J., Wang, Z., Wang, P.: Safety Climate Measurement at Workplace in China: A Validity and Reliability Assessment. Safety Science 46, 10371046 (2008)

6. Ma, Q., Yuan, J.: Exploratory Study on Safety Climate in Chinese Manufacturing Enterprises. Safety Science 47(7), 1043-1046 (2009)

7. $\mathrm{Wu}, \mathrm{X}$., Piao, Y., Fang, X.: Investigation on Nurses' Perception on Hospital Safety Culture. Journal of Nursing Science 24, 7-9 (2009) (in Chinese)

8. Liu, Y., Kalisch, B.J., Zhang, L., Xu, J.: Perception of Safety Culture by Nurses in Hospitals in China. Journal of Nursing Care Quality 24(1), 63-68 (2008)

9. Itoh, K., Andersen, H.B.: A National Survey on Healthcare Safety Culture in Japan: Analysis of 20,000 Staff Responses from 84 Hospitals. In: Proceedings of the International Conference on Healthcare Systems Ergonomics and Patient Safety, HEPS 2008, Strasbourg, France (June 2008) (CD-ROM)

10. Guldenmund, F.W.: The Nature of Safety Culture: A Review of Theory and Research. Safety Science 34(1-3), 215-257 (2000)

11. Madsen, M.D., Andersen, H.B., Itoh, K.: Assessing Safety Culture and Climate in Healthcare. In: Carayon, P. (ed.) Handbook of Human Factors and Ergonomics in Healthcare and Patient Safety, pp. 693-713. Lawrence Erlbaum Associates, Mahwah (2007)

12. Itoh, K., Abe, T., Andersen, H.B.: A Questionnaire-based Survey on Healthcare Safety Culture from Six Thousand Japanese Hospital Staff: Organisational, Professional and Department/Ward Differences. In: Proceedings of the International Conference on Healthcare Systems Ergonomics and Patient Safety, HEPS 2005, Florence, Italy, MarchApril 2005, pp. 201-207 (2005)

13. Helmreich, R.L., Merritt, A.C.: Culture at Work in Aviation and Medicine: National, Organizational and Professional Influences. Ashgate, Aldershot (1998)

14. Andersen, H.B., Madsen, M.D., Hermann, N., Schiøler, T., Østergaard, D.: Reporting Adverse Events in Hospitals: A Survey of the Views of Doctors and Nurses on Reporting Practices and Models of Reporting. In: Johnson, C. (ed.) Proceedings of the Workshop on the Investigation and Reporting of Incidents and Accidents, Glasgow, UK, July 2002, pp. 127-136 (2002)

15. Bland, J.M., Altman, D.G.: Statistics Notes: Cronbach's Alpha. British Medical Journal 314(7080), 572 (1997)

16. Schmitt, N.: Uses and Abuses of Coefficient Alpha. Psychological Assessment 8(4), 350 353 (1996)

17. Spiliotopoulou, G.: Reliability Reconsidered: Cronbach' Alpha and Paediatric Assessment in Occupational Therapy. Australian Occupational Therapy Journal 56(3), 150-155 (2009) 